\title{
A climatological perspective of deep convection penetrating the TTL during the Indian summer monsoon from the AVHRR and MODIS instruments
}

\author{
A. Devasthale ${ }^{1}$ and S. Fueglistaler ${ }^{2}$ \\ ${ }^{1}$ Remote Sensing Division, Swedish Meteorological and Hydrological Institute, Norrköping, Sweden \\ ${ }^{2}$ Department of Applied Mathematics and Theoretical Physics, University of Cambridge, Cambridge, UK
}

Received: 7 November 2009 - Published in Atmos. Chem. Phys. Discuss.: 4 February 2010

Revised: 18 April 2010 - Accepted: 6 May 2010 - Published: 18 May 2010

\begin{abstract}
The impact of very deep convection on the water budget and thermal structure of the tropical tropopause layer is still not well quantified, not least because of limitations imposed by the available observation techniques. Here, we present detailed analysis of the climatology of the cloud top brightness temperatures as indicators of deep convection during the Indian summer monsoon, and the variations therein due to active and break periods. We make use of the recently newly processed data from the Advanced Very High Resolution Radiometer (AVHRR) at a nominal spatial resolution of $4 \mathrm{~km}$. Using temperature thresholds from the Atmospheric Infrared Sounder (AIRS), the AVHRR brightness temperatures are converted to climatological mean (20032008) maps of cloud amounts at 200, 150 and $100 \mathrm{hPa}$. Further, we relate the brightness temperatures to the level of zero radiative heating, which may allow a coarse identification of convective detrainment that will subsequently ascend into the stratosphere. The AVHRR data for the period 1982-2006 are used to document the differences in deep convection between active and break conditions of the monsoon. The analysis of AVHRR data is complemented with cloud top pressure and optical depth statistics (for the period 2003-2008) from the Moderate Resolution Imaging Spectroradiometer (MODIS) onboard Aqua satellite. Generally, the two sensors provide a very similar description of deep convective clouds.

Our analysis shows that most of the deep convection occurs over the Bay of Bengal and central northeast India. Very deep convection over the Tibetan plateau is comparatively weak, and may play only a secondary role in troposphere-tostratosphere transport. The deep convection over the Indian
\end{abstract}

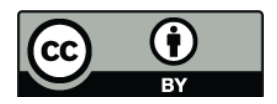

Correspondence to: A. Devasthale (abhay.devasthale@smhi.se) monsoon region is most frequent in July/August, but the very highest convection (coldest tops, penetrating well into the TTL) occurs in May/June. Large variability in convection reaching the TTL is due to monsoon break/active periods. During the monsoon break period, deep convection reaching the TTL is almost entirely absent in the western part of the study area (i.e. $60 \mathrm{E}-75 \mathrm{E}$ ), while the distribution over the Bay of Bengal and the Tibetan Plateau is less affected. Although the active conditions occur less frequently than the break conditions, they may have a larger bearing on the composition of the TTL within the monsoonal anticyclone, and tracer transport into the stratosphere because of deep convection occurring over anthropogenically more polluted regions.

\section{Introduction}

The gradual transition from the thermally direct tropospheric Hadley/Walker-circulation to the wave-driven stratospheric Brewer-Dobson circulation gives rise to a layer with both tropospheric and stratospheric characteristics, termed the tropical tropopause layer (TTL; Highwood and Hoskins, 1996; Sherwood and Dessler, 2000; Gettelman and Forster, 2002; Fueglistaler et al., 2009a). Despite massive efforts both from an observational and model perspective, the vertical profile of the importance of convective transport versus eddy-driven dynamics remains poorly quantified in the TTL (Fueglistaler et al., 2009a), with implications for climate forecasts in general, and troposphere-stratosphere exchange in particular.

In this context, the Indian monsoon region is of particular interest. On the one hand, convection during the Indian monsoon, in particular also over the Bay of Bengal, is known to be exceptionally deep (Gettelman et al., 2002; Devasthale

Published by Copernicus Publications on behalf of the European Geosciences Union. 


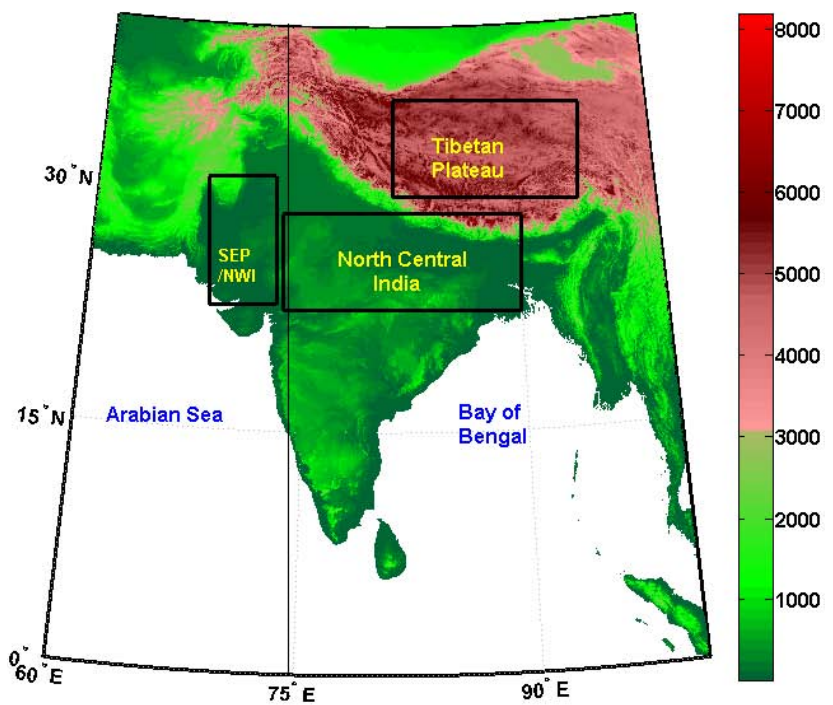

Fig. 1. The topography (color coded, in meters above sea level) of the sector analysed in this paper. The black line at $75 \mathrm{E}$ indicates the separation for spatial aggregation in the analysis of active and break periods of the monsoon. The boxes "Tibetan Plateau" and "North Central India" identify the regions mentioned in the text. The land and sea areas in this entire study area are considered later for the analysis.

and Grassl, 2009b). On the other hand, the horizontal circulation at upper tropospheric levels and throughout the TTL is governed by a large anticylone spanning the area from the Arabian Peninsula to Southeast Asia (i.e. about $10000 \mathrm{~km}$ in longitude). Observations show high water vapour, low ozone and high $\mathrm{CO}$ concentration within the anticyclone at TTL levels (e.g. Dessler and Sherwood, 2004; Park et al., 2008). The strong anticyclonic flow implies substantial isolation of air masses within the anticyclone (Park et al., 2008), which may be punctuated from below by deep convection. While Fu et al. (2007) emphasize the importance of convection over the Tibetan Plateau, James et al. (2008) locate the main source region south of the Himalayas over the Indian subcontinent, Bay of Bengal, and Southeast Asia.

Here, we characterize deep convection (in terms of maps of cloud top height distributions) using data from the Advanced Very High Resolution Radiometer (AVHRR) and the Moderate Resolution Imaging Spectroradiometer (MODIS) sensors. Numerous studies used data from cloud observing sensors to characterize deep convection (e.g. Alcala and Dessler, 2002; Dessler et al., 2006; Fu et al., 2007; Gettelman et al., 2002; Haladay and Stephens, 2009; Hong et al., 2008; Jiang et al., 2004; Liu and Zipser, 2006; Rossow and Pearl, 2007). Here, we extend these earlier studies (often using data at a coarse resolution and/or over a limited time period only) with an analysis of the vertical structure, geographical distribution and their variability of deep convection during the Indian monsoon in unprecedented detail.
For reference, Fig. 1 shows the topography of the area of interest, and the names of locales and regions specifically discussed in this paper.

The paper is structured as follows. Section 2 discusses the data and methods. Section 3 shows the results (in terms of distributions of deep convection) and discussions, and, finally, Sect. 4 provides a summary and brief outlook.

\section{Data and methods}

\subsection{The AVHRR data}

The level 1b Global Area Coverage (GAC) dataset at the nominal resolution of $4 \mathrm{~km}$ from the AVHRRs is used in the study. The AVHRR is a five-channel instrument. Two channels are in the solar spectrum $(0.58-0.68 \mu \mathrm{m}$ and 0.725 $1.1 \mu \mathrm{m})$ and two are in the thermal infrared spectrum (10.3$11.3 \mu \mathrm{m}$ and $11.5-12.5 \mu \mathrm{m})$. The third channel falls partly in the solar and in the thermal infrared spectrums (3.55$3.93 \mu \mathrm{m})$. This dataset is introduced and documented in detail by Devasthale and Grassl (2009a, b). Of particular importance here is the accurate calibration and inter-calibration of the AVHRR thermal channels in this data product. Despite a few uncertainties in the thermal channel calibration assembly, the measurement noise (i.e. noise equivalent delta error, NEdT) in the thermal channels is as low as about $0.15 \mathrm{~K}$ to $0.35 \mathrm{~K}$ at $200 \mathrm{~K}$ brightness temperature for different AVHRR instruments (Trishchenko et al., 2002). Further, the high radiometric resolution (10-bits) yields high calibration accuracy even at very cold brightness temperatures (around $0.25 \mathrm{~K}$ at $190 \mathrm{~K}$ brightness temperature, due to finer digitization of count to radiances) compared to, for example, MVIRI/Meteosat-5.

For the conversion from measured brightness temperature by AVHRR to an estimate of cloud top, we use monthly mean temperature data obtained from AIRS. The AIRS instrument provides very accurate temperature data during the study period, and as an additional precaution, the monthly mean temperature climatologies are constructed only from profile where both AIRS and MODIS (both on board of the Aqua satellite) cloud masks indicate cloud free profiles.

If the AVHRR channel 4 brightness is less than the temperature from AIRS at a given pressure level (in this study $200 \mathrm{hPa}, 150 \mathrm{hPa}, 100 \mathrm{hPa}$ ), we assume that convection may have reached that particular pressure level. Note that the occurrence of deep convection will alter the temperature profile somewhat compared to the clear sky case taken as reference. This local perturbation might affect absolute numbers on a given level but should not introduce significant biases with respect to the spatial distribution and its variability.

The contribution to signal at channel 4 (wavelength 10.511.5 microns) essentially comes from the top of cloud when the optical thickness approximately becomes larger than 10 . In such cases, the detected cloud is geometrically thick and 

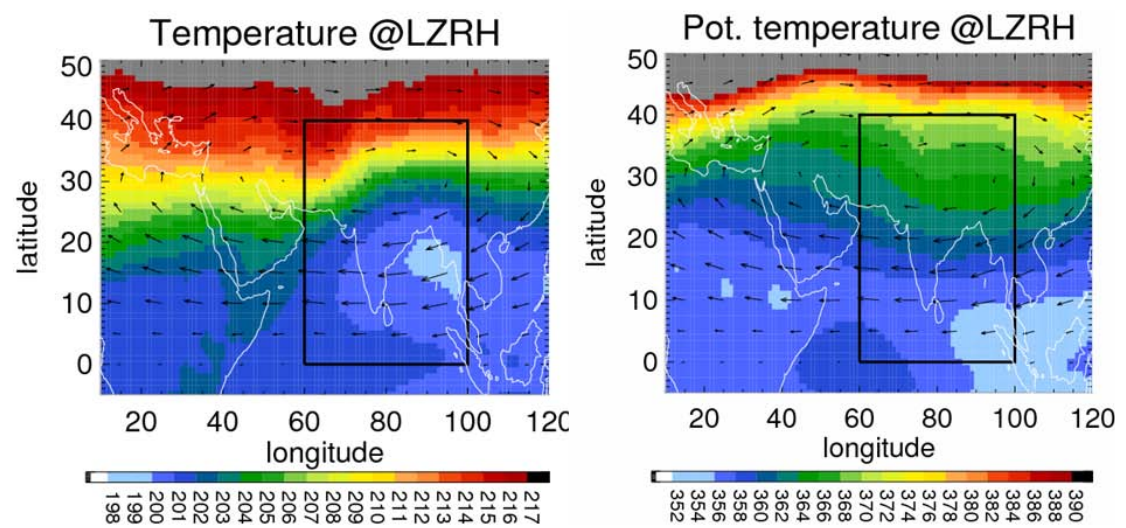

Fig. 2. The clear sky level of zero radiative heating from ECMWF ERA-Interim radiative transfer calculations. Color-coded is the temperature (left) and potential temperature (right) in Kelvin, with arrows showing the wind on this level. Data shown is the June-September average of the year 2000 .

opaque representing either convective core or its trace (optically thick anvil cirrus or convective cloud debris). The in situ formed cirrus clouds in the TTL are, on the other hand, necessarily optically thin (because of very little water available for condensation) and consequently may not be detected by AVHRR. Finally, note that the heights determined from brightness temperatures represent an "effective" cloud top, and do not refer to the uppermost level where condensate is present (as would a measurement from a downlooking lidar, for example), and the cloud top height estimate may be biased low by about 1-2 km (Sherwood et al., 2004). While this deficit again should not bias the distribution patterns, the cloud fractions on a given pressure level determined from AVHRR should be seen as conservative estimates.

\subsection{MODIS and Meteosat-5 data}

The cloud fraction analysis based on AVHRR data is complemented with data from MODIS and Meteosat-5. MODIS (on Aqua) level 2 version 5 cloud products (King et al., 2003) are used. We use the MODIS cloud optical depth and cloud top pressure data to characterize high clouds in two-dimensional space for the monsoons seasons of 2003-2008. As we are interested in optically thicker clouds in this study, we are not concerned about possible underestimation of optically very thin cirrus clouds by MODIS.

The three sensors AVHRR, AIRS and MODIS are mounted on afternoon polar orbiting platforms. However, small biases may still occur due to different sampling times of diurnal variations of deep convection from NOAA-16 and Aqua platforms. We estimate the influence of the sampling time with measurements from the geostationary Meteosat5 satellite, using brightness temperature measurements from the thermal channel (10.5-12.5 micrometers) of MVIRI sensor. This allows the characterization of the diurnal cycle at very high temporal resolution but at the cost of less radiometric and spectral resolution than AVHRRs.
It is to be noted here that since the cloud optical thickness and some of the thresholds to delineate opaque high clouds can only be computed using solar channels, we provide only daytime estimates of cloud amounts from AVHRRs and MODIS due to these algorithm constraints.

\subsection{The level of zero radiative heating (LZRH)}

In addition to cloud fraction estimates on fixed pressure levels, we also relate the observed brightness temperatures to the level of zero radiative heating (LZRH), which may be a sensible level to identify convective detrainment that subsequently directly enters the stratosphere (further discussed below). We use the radiative transfer calculations of the ECMWF ERAInterim data (see Fueglistaler et al., 2009b) to determine the height, temperature and potential temperature of the clear sky LZRH. It is well known that clouds strongly affect the radiative balance, and as such the all sky LZRH becomes a highly variable level in cloudy regions. Moreover, cloud radiative heating depends strongly on details of a model's cloud scheme, and the true cloud radiative heating is currently not well known. We, therefore, use the clear sky LZRH as a conservative level (clouds tend to lower the LZRH).

Figure 2 shows the temperature and potential temperature of a typical monsoon season (June-September 2000) of the LZRH. The figure shows clearly that even the clear sky LZRH has substantial structure in the area of interest, such that an air parcel may experience radiative heating and cooling as it travels within the monsoonal anticyclone. In particular, one may be concerned that air detraining e.g. over the Bay of Bengal may be advected with the monsoonal anticyclonic flow into a region where the LZRH has a higher potential temperature, and subsequently may subside back into the troposphere. A full Lagrangian analysis is warranted to address these issues, which is beyond the scope of this paper. As a rough guidance, we note that radiative heating and cooling at these levels is of order $0.1-1 \mathrm{~K} /$ day in potential 

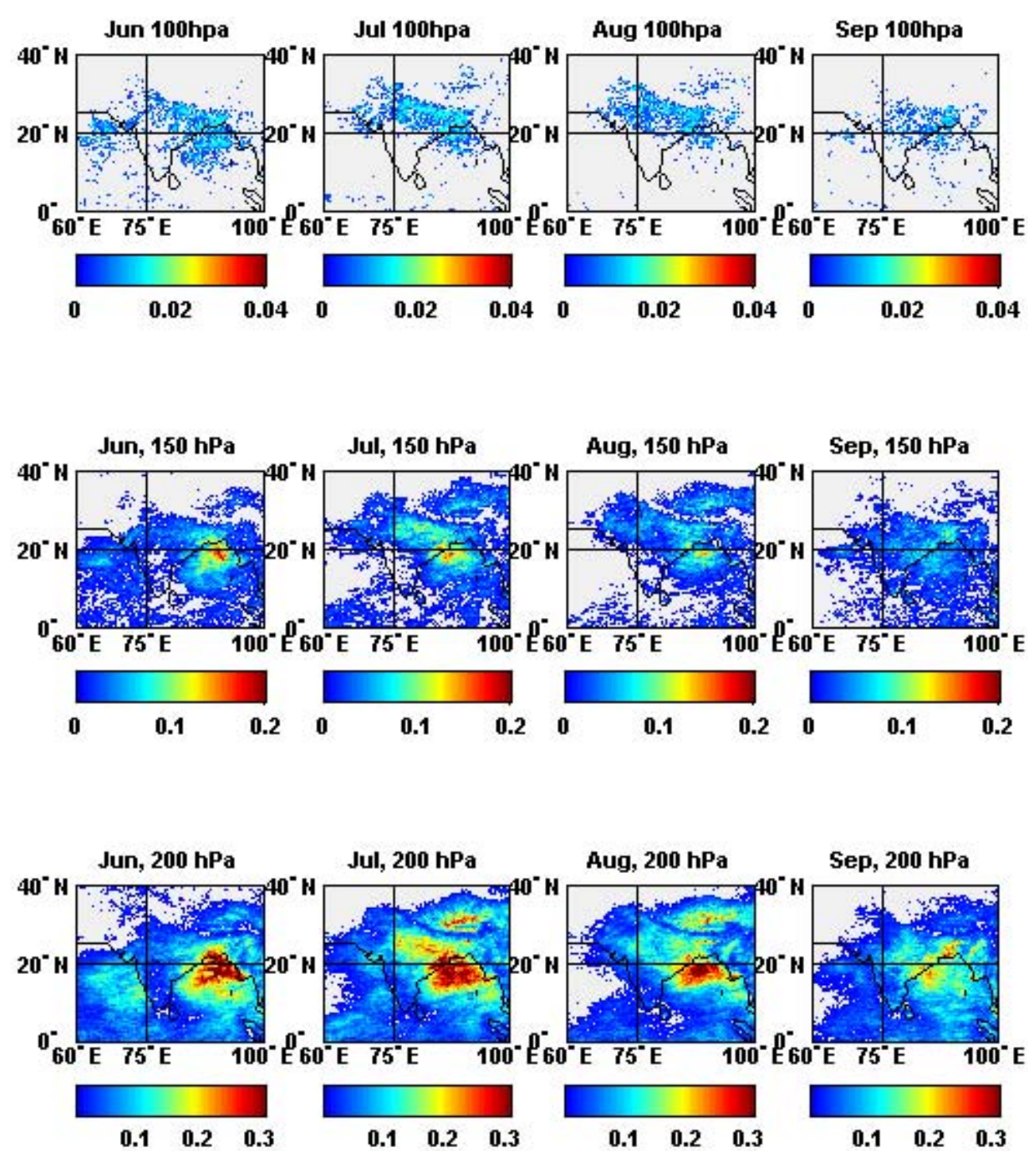

Fig. 3. Cloud fraction from AVHRR at $100 \mathrm{hPa}$ (top row), $150 \mathrm{hPa}$ (middle row) and at $200 \mathrm{hPa}$ (bottom row). The spatial resolution is $0.1 \times 0.1$ degrees. Data shown is climatological mean of the period 2003-2008; temperature data from AIRS is used to compute cloud fraction from AVHRR brightness temperatures.

temperature, and a typical residence time e.g. in the northern part of the anticylone may be 2 days, resulting in an ambiguity of the level separating ascent from descent of less than $2 \mathrm{~K}$ in potential temperature. This is of similar order as the expected effects of clouds, i.e. the level of zero net radiative heating in the presence of clouds may also be, in potential temperature, a few Kelvin lower. We emphasize that the LZRH should only be viewed as a physically more meaningful indicator than a certain pressure level, and that clouds and the advection of the flow introduces some ambiguity with respect to the level at which convective detrainment eventually enters the stratosphere.

\section{Results}

\subsection{The climatological mean distribution of deep convection}

Figure 3 shows the climatological mean spatial distribution of AVHRR brightness temperatures lower than the temperatures at 200,150 and $100 \mathrm{hPa}$, respectively. As pointed out in Sect. 2, these fraction may be interpreted as the presence of opaque ice clouds which are either very deep convective clouds or related thick anvil cirrus. At $100 \mathrm{hPa}$, they are most likely very deep convective cores. Broadly speaking, the AVHRR data suggest a decrease in the fractional coverage of deep convective clouds by an order of magnitude between $200 \mathrm{hPa}$ and $100 \mathrm{hPa}$. 

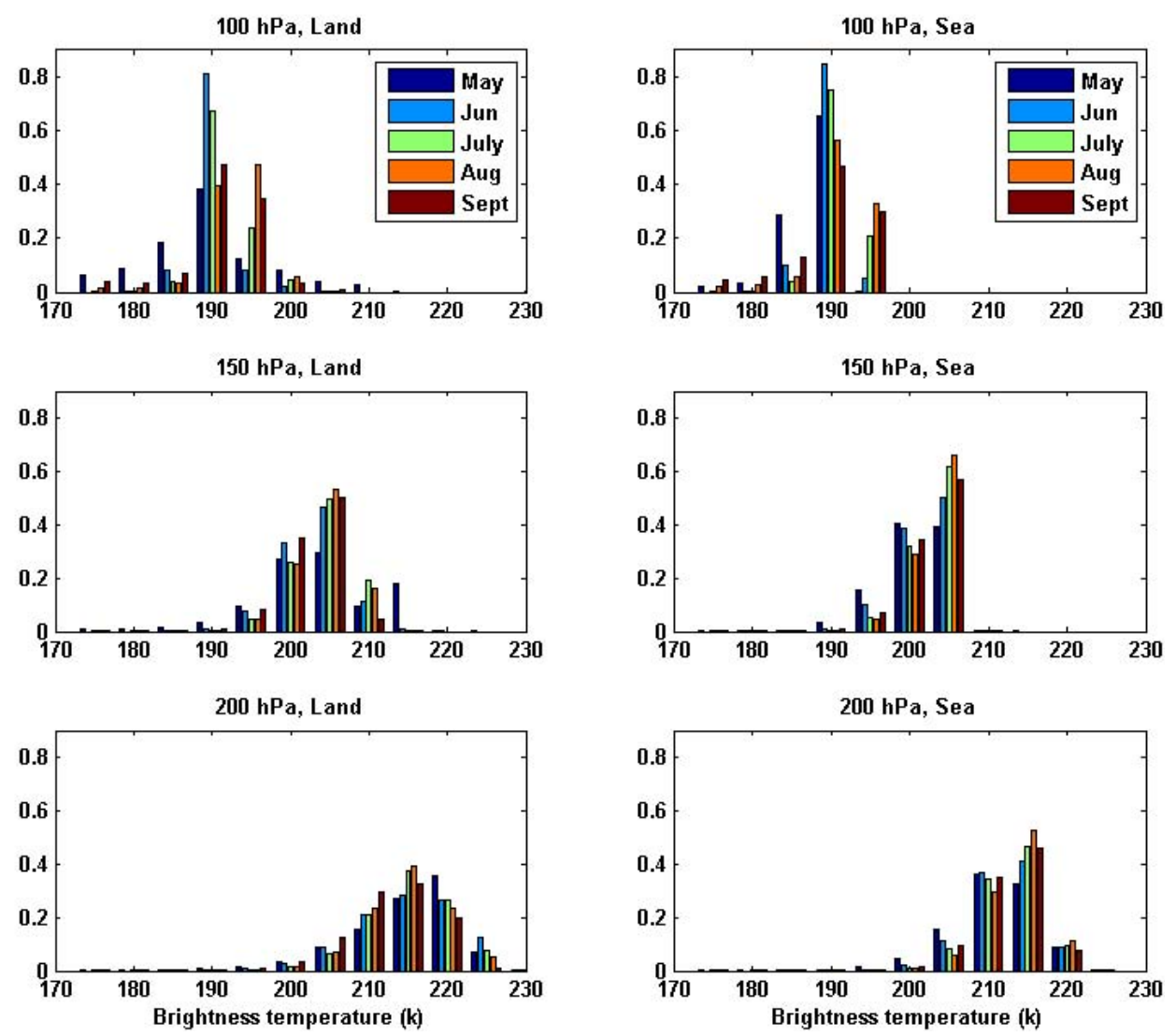

Fig. 4. Frequency distribution of the cloud top brightness temperatures from AVHRR binned into $5 \mathrm{~K}$ intervals) with cloud tops higher than $200 \mathrm{hPa}$ (bottom row), $150 \mathrm{hPa}$ (middle row) and $100 \mathrm{hPa}$ (top row). The left column shows the frequency distribution for land areas only, while the right column shows for sea areas only. The entire study area shown in Fig. 1 is considered for the analysis. Note that the figures show the statistics of all brightness temperatures lower than the temperature of the corresponding pressure levels, and as such the statistics for, e.g. the $200 \mathrm{hPa}$ level includes those event that reach higher than $150 \mathrm{hPa}$ or even $100 \mathrm{hPa}$.

Consistent with previous studies (e.g. Devasthale and Grassl, 2009b), the AVHRR data shows the progression of deep convection from the Bay of Bengal region during the early stage of the monsoon (June) to the northeastern India and the Ganges Basin, and subsequent retreat during the decay of the monsoon (September). The very high resolution of the data allows a very accurate geographic positioning of the deep convection. The sharp northern boundary is due to the presence of the Himalayas. Further north, deep convection particularly during July and August is observed over the Tibetan Plateau. Note that at $200 \mathrm{hPa}$ the cloud fractions over the Tibetan Plateau are similar to those south of the Himalayas, while at $100 \mathrm{hPa}$ the spatial distribution is clearly dominated by convection south of the Himalayas.

\subsection{Progression of deep convection, and land-sea differences}

Figure 4 separates the measurements between convection over land and over sea for the entire study area shown in Fig. 1. The figure shows that while deep convection (reach- ing at least 200 and $150 \mathrm{hPa}$ ) is most frequent in July and August, it is in May and June that the coldest cloud tops are observed (both over land and sea), suggesting more direct convective injections into the TTL in this area in the early stages of the monsoon season.

Further, we note that the brightness temperatures of deep convection over the land portions of the study area have a broader and less skewed distribution. This difference is also a consequence of the larger variability of temperatures on a fixed pressure level over the land areas than over sea in the study area (see also the temperature distribution on the LZRH, shown in Fig. 2a). These temperature variations are a consequence of the large scale dynamics as well as the direct influence of the convection on the thermal structure in regions of frequent deep convection.

\subsection{Changes in deep convection between active and break monsoon conditions}

One of the intrinsic characteristics of the Indian summer monsoon is the intraseasonal oscillations in rainfall, which 

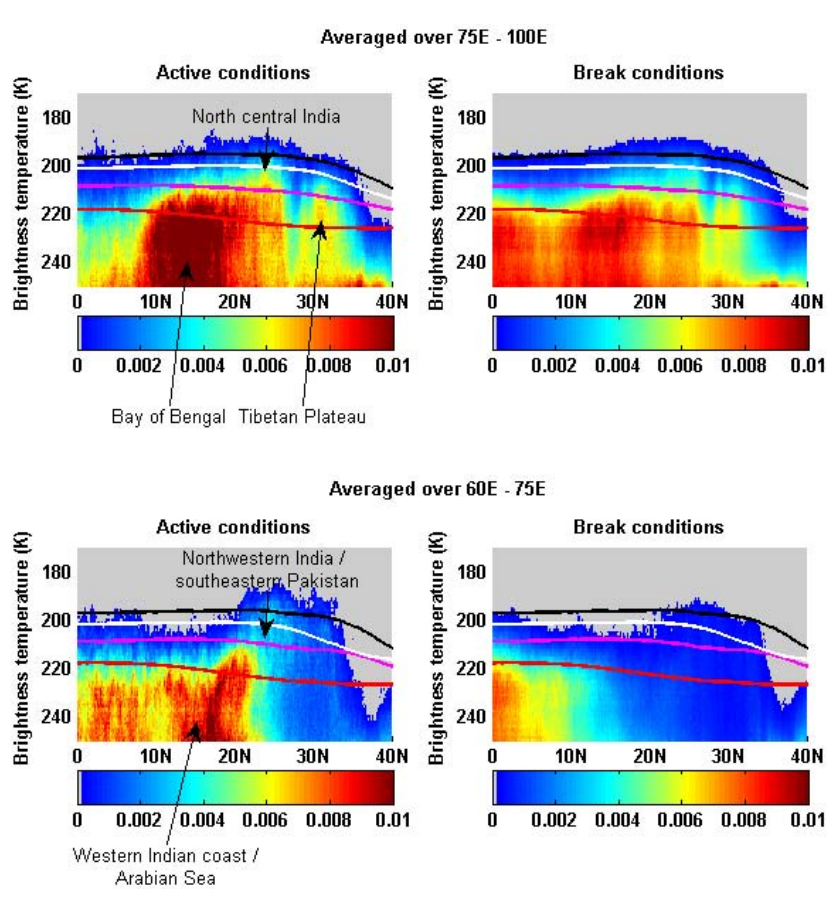

Fig. 5. The distribution (bin sizes of 0.1 degrees latitude by $1 \mathrm{~K}$ brightness temperature; each latitude bin is normalized by the total number of observations (cloudy+clear) at all longitudes as indicated in the figure) of high opaque clouds during active and break monsoon conditions for the eastern and the western parts of the study area (shown in Fig. 1 above). The black, magenta, and red lines are the mean temperatures at $100 \mathrm{hPa}, 150 \mathrm{hPa}$ and $200 \mathrm{hPa}$ derived from AIRS, while white line is the typical level of zero radiative heating from ERA-Interim (averaged June-September 2000).

are related to fluctuations in the ITCZ (Goswami and Ajaya Mohan, 2001). The intraseasonal oscillations are manifested through the active and break monsoon conditions. Two dominant modes of oscillations are observed, one with 10-20 day period and the other with $30-60$ day period. The spatial pattern of convective cloud amount is vividly different during active and break conditions (Devasthale and Grassl, 2009b), which may have implications for tracer transport into the TTL.

We separated the AVHRR measurements according to the most recent definition by Rameh Kumar and Uma (2004) of active versus break monsoon periods. In order to have good statistics, we use AVHRR data for the period 19822006 ( 25 monsoon seasons), resulting in 138 active and 633 break days in July and August. Note that, in absence of AIRS temperatures for most of this period, we analyse the data in terms of brightness temperature frequencies.

Figure 5 shows the vertical (with temperature as vertical axis) structure, and its latitudinal variation, of convection averaged between $60 \mathrm{E}-75 \mathrm{E}$, and $75 \mathrm{E}-100 \mathrm{E}$ (as indicated by the separation line in Fig. 1). For orientation, the figure also shows the climatological (2003-2008) mean tempera- tures at 200, 150 and $100 \mathrm{hPa}$ from AIRS. Moreover, the figures show the temperature of the level of zero radiative heating, as discussed in Sect. 2.3.

Substantial differences in the amount and the spatial pattern of these clouds can be seen in the two contrasting monsoon conditions. During the active monsoon periods, the bulk of deep convection is observed between about $10 \mathrm{~N}$ and $25 \mathrm{~N}$, with the dominant regions being central India, northern Bay of Bengal, and the western coast of India. Moreover, during the active periods the convection tends to be deeper. An interesting point we will return to later is that the AVHRR data shows the deepest convection to occur along the south slopes of the Himalayas (northwestern and north central India), rather than the Bay of Bengal as proposed in previous studies.

During the monsoon break period, deep convection is almost entirely absent in the western part of the study area (i.e. $60 \mathrm{E}-75 \mathrm{E}$ ), while the distribution over the Bay of Bengal (Fig. 5, upper panels; identified by latitudes between about $15 \mathrm{~N}$ to $25 \mathrm{~N}$ ) and the Tibetan Plateau (Fig. 5, upper panels; identified by latitudes around $30 \mathrm{~N}$ ) is less affected.

Although the active conditions occur less frequently than the break conditions, they may have a larger bearing on the composition of the TTL within the monsoonal anticylone, an aspect to be borne in mind for the interpretation of studies based on models that may not capture these variations in the spatial structure of deep convection. In particular, anthropogenic pollution is concentrated in central/northeast India (for example, see Di Girolamo et al., 2004; Prasad et al., 2006), and these polluted air masses may (during active monsoon periods) or may not (during monsoon break periods) reach the TTL.

\subsection{Deep convection and high clouds from MODIS data}

We complement the highly detailed measurements from AVHRR of brightness temperatures with data from MODIS (Level 2, version 5), which provides retrievals of cloud optical thickness and cloud top pressure. Figure 6 shows the climatological mean (2003-2008) histogram of optical depth of clouds over the study area (i.e. 0-40 N, 60-100 E) for the period June to September (JJAS).

The most prominent feature of this distribution is the dominance of clouds with optical depths less than 23 at pressure levels of 250 and $200 \mathrm{hPa}$, which can be attributed to cirrus and cirrostratus resulting from convective detrainment peaking at these levels. In order to focus on the convective cores that penetrate deeply into the TTL, we analyse clouds that have very large optical thickness (greater than 23).

Figure 7 shows the spatial distribution of these optically thick convective clouds with a top higher than $100 \mathrm{hPa}$. The spatial distribution is remarkably similar to that obtained from AVHRR (compare with Fig. 3, top row) indicating that the clouds that penetrate above $100 \mathrm{hPa}$ are most likely to be the cores of deep convection. There are, however, also 


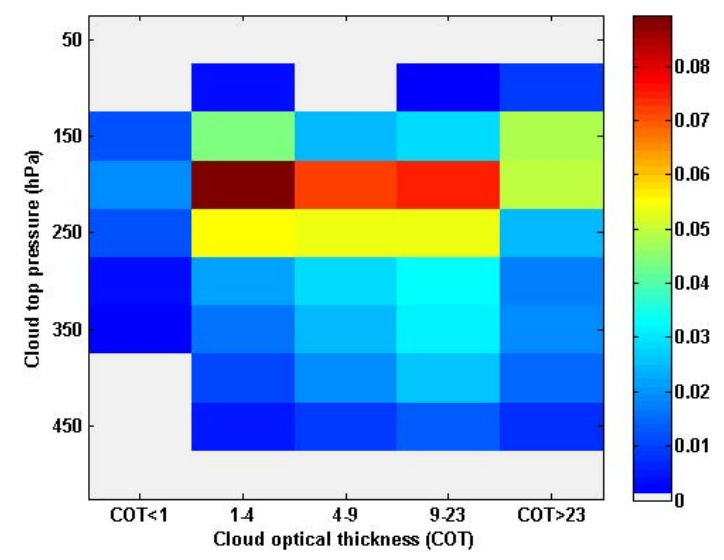

Fig. 6. The 2-D histogram of cloud optical thickness and cloud top pressure from the MODIS data for June, July, August and September months from 2003 to 2008 . The histogram is normalized by the total number of cloudy pixels in the study area (i.e. $0-40 \mathrm{~N}, 60$ $100 \mathrm{E})$.

some differences between the two data sets. Perhaps the most prominent difference is that the MODIS data show larger cloud fractions (Fig. 7) in particular over the Ganges Basin. These differences may arise from the slightly different sampling time of the two instruments (further complicated by a drift in sampling time of NOAA-16 by up to $2 \mathrm{~h}$ during its life span), different methodologies to estimate cloud height (AVHRR uses AIRS profiles, while MODIS uses a $\mathrm{CO}_{2}$ slicing technique), and lack of cross-calibration (accounting for differences in the spectral response functions of the channels) between the sensors. These factors render a comparison between AVHRR and MODIS results difficult, but we consider the very good overall agreement highly encouraging, suggesting that both data sets provide a reliable description of the afternoon deep convection in the area of interest.

The zonal distribution of all clouds as a function of cloud top pressure is shown in Fig. 8, and the relative fraction of these clouds with optical optical thickness greater than 23 (i.e. deep convective clouds as per ISCCP definition) is shown in Fig. 9. About 35-40\% of all clouds have their tops at $200 \mathrm{hPa}$ during all monsoon months (Fig. 8). Most of these clouds are cirrus or cirrostratus, while the deep convective clouds (i.e. optical depth $>23$ ) dominate at the $100 \mathrm{hPa}$ layer (Fig. 9).

Comparison of the cloud fractions shown in Fig. 8, and the fraction thereof of deep convective clouds shown in Fig. 9, shows that most clouds observed at $100 \mathrm{hPa}$ are thick convective clouds (with optical thicknesses $>23$ ). On the contrary, among all clouds observed at $200 \mathrm{hPa}$ the majority of clouds do not fall into the optically thick convective cloud category. That is, at $200 \mathrm{hPa}$, MODIS mostly detects relatively thin clouds with optical depths in the range 1 to 23 . The in-situ formed cirrus clouds at $100 \mathrm{hPa}$ are optically much thinner (with optical thickness $\ll 0.3$ ) than those at $200 \mathrm{hPa}$. In many
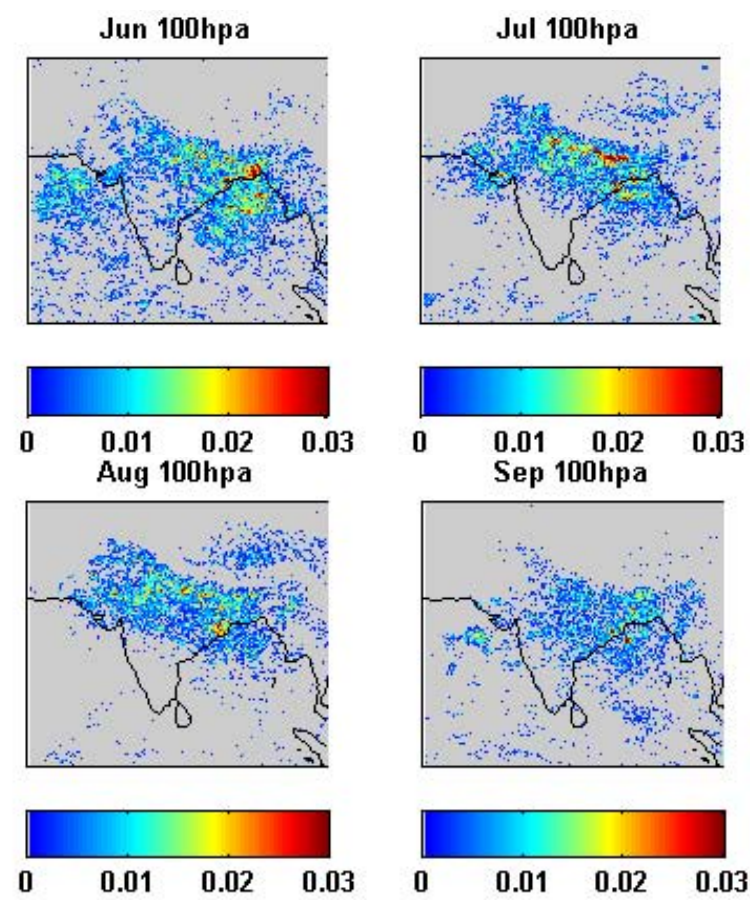

Fig. 7. The composite of cloud amount at $100 \mathrm{hPa}$ from seen from the MODIS averaged over 2003 to 2008 (for clouds with optical thickness greater than 23). Note that the color-scale is identical to that of Fig. 3, $100 \mathrm{hPa}$ data.
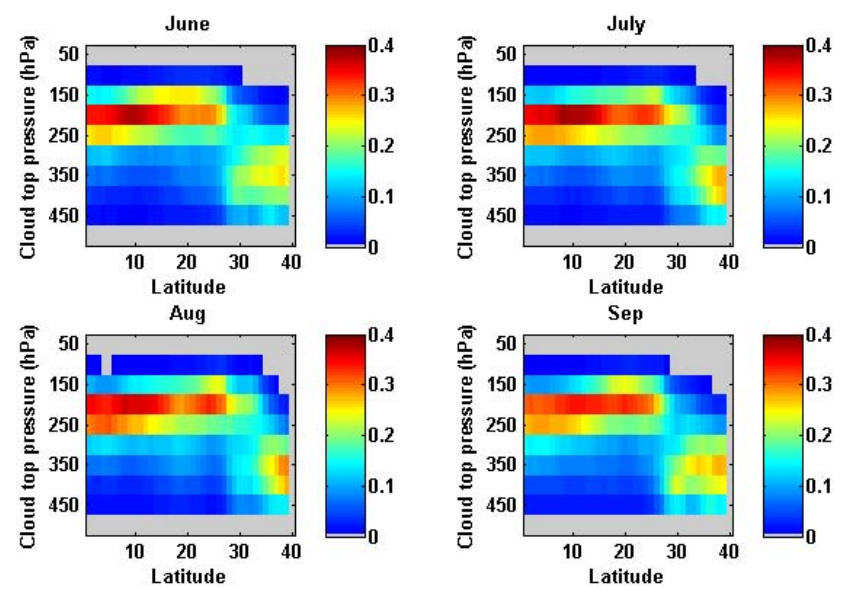

Fig. 8. The latitudinal structure (zonal mean $60 \mathrm{E}-100 \mathrm{E}$ ) of cloud top pressure occurrence frequency from MODIS. Each latitude bin is normalized by the total number of cloudy observations in that bin (i.e. the cumulative distribution with height is 1 for each latitude bin).

cases, such subvisual cirrus clouds may not be detected by MODIS, thus underestimating their fraction at $100 \mathrm{hPa}$ level. Thin cirrus clouds are not the focus of this paper, but these observations provide a clear example of the challenges encountered to provide unbiased analyses of clouds. 

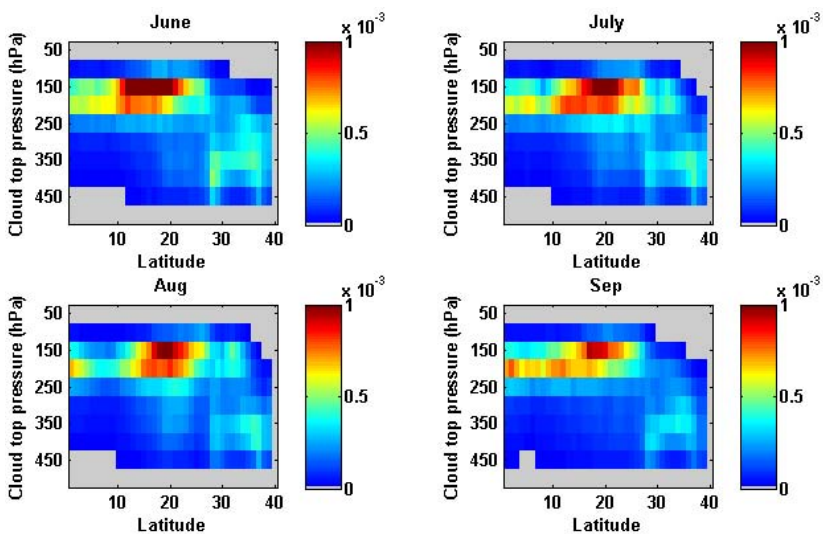

Fig. 9. The relative fraction of clouds as shown in Fig. 8 with optical thickness greater than 23 (i.e. only deep convective clouds as per the definition by the ISCCP).

\subsection{The diurnal cycle of deep convection}

In the previous section we have shown observations of very deep convection from AVHRR and MODIS. In order to make robust conclusions about the relative convective cloud amounts over the Bay of Bengal, central northeast India and the Tibetan Plateau, great care must be taken that observed patterns and cloudiness magnitudes are not artifacts due to the inconsistent sampling of the diurnal cycle of deep convection.

Both AVHRR and MODIS are mounted on afternoon satellites. They sample the diurnal cycle of convection only at a fixed time of the day. As the observation time in general is not coincident with the time of local maximum deep convective activity, occurrence frequency estimates of deep convection from these platforms tend to be biased low. For an analysis of spatial and temporal variability this bias may be less of a problem unless the bias has a spatio-temporal structure. Moreover, measurements from different observation times (as e.g. in the case of AVHRR and MODIS) may not be directly comparable.

In order to estimate how the sampling time affects the results, we have derived brightness temperature statistics from MVIRI/Meteosat-5.

Figure 10 shows the full diurnal cycle of brightness temperature frequencies for three sub-regions (central northeast India, Bay of Bengal and Tibetan Plateau) of our study area. The figure shows that the maxima are observed within about an hour in central northeast India and the Tibetan Plateau regions and at both levels (i.e. $210 \mathrm{~K}$ and $230 \mathrm{~K}$ ), with the maximum of deep convection (brightness temperature below $210 \mathrm{~K}$ ) over the Tibetan Plateau being about one hour earlier than over central India. While it cannot be excluded that this shift in timing might affect a comparison of occurrence frequency between these two regions, it is important to note that the absolute difference in frequency between these two

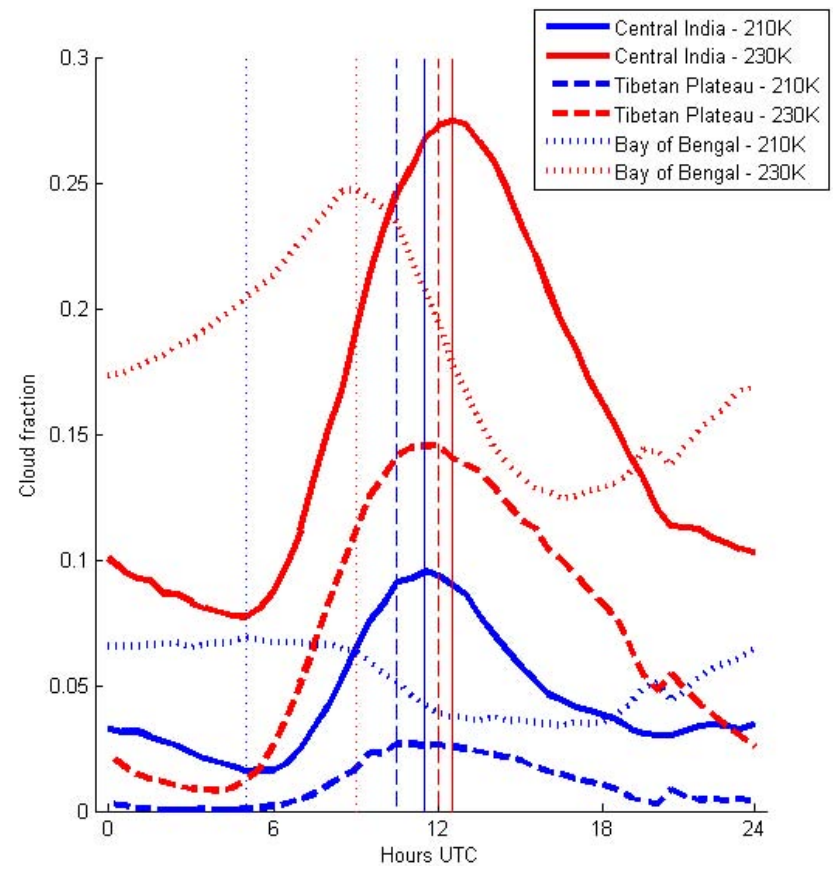

Fig. 10. The comparison of diurnal cycles of convection over the central India, Bay of Bengal and the Tibetan Plateau. The diurnal cycles are derived using Meteosat- 5 data for the monsoon seasons of 2002 and 2003. The vertical lines indicate the time of maximum cloud fraction.

regions is much larger than the differences introduced by the different sampling time relative to the local phase of the diurnal cycle. The same is true for the Bay of Bengal region when compared to the Tibetan Plateau.

\section{Summary and outlook}

Using synergistic analysis of AVHRR, MODIS and AIRS data, the present study provides a climatological view of opaque high clouds in the TTL. The high resolution of the measurement allows an analysis of the spatial distribution and variations during active and break monsoon conditions in unprecedented detail. It is shown that a significant fraction of high opaque clouds (in the latitude belt of $10 \mathrm{~N}-25 \mathrm{~N}$ ) reaches and penetrates into the TTL during active monsoon conditions, while they tend to be persistently equator wards during break conditions. The overall frequency of convective clouds (reaching at least $200 \mathrm{hPa}$ ) is higher in the months of July and August than May and June; however, deepest intrusions (reaching at least $100 \mathrm{hPa}$ ) occur during May and June. This conclusion is valid for convective clouds both over the land and the sea areas. While there is some difference in the frequency of very deep convection between AVHRR and MODIS in particular over the Bay of Bengal, the statistics from the two instruments generally agree quite well. Both instruments suggest that deep convection over the Tibetan 
Plateau plays only a secondary role compared to that over the Bay of Bengal and northeastern India. These findings do not support the suggested eminent role of the Tibetan Plateau for troposphere-to-stratosphere transport (Fu et al., 2006), but more detailed studies linking high resolution cloud top data such as used here to troposphere-to-stratosphere transport are required to accurately quantify the different pathways.

Acknowledgements. The authors would like to thank CLASS/NOAA and DAAC/NASA for making AVHRR, AIRS and MODIS data freely available. AD would like to thank Julian Kuhlmann (MPI Hamburg, Germany) for helping in the MODIS data processing.

Edited by: P. Spichtinger

\section{References}

Alcala, C. M. and Dessler, A. E.: Observations of deep convection in the tropics using the Tropical Rainfall Measuring Mission (TRMM) precipitation radar, J. Geophys. Res., 107(D24), 4792, doi:10.1029/2002JD002457, 2002.

Corti, T., Luo, B. P., de Reus, M., et al.: Unprecedented evidence for deep convection hydrating the tropical stratosphere, Geophys. Res. Lett., 35, L10810, doi:10.1029/2008GL033641, 2008.

Dessler, A. E., Palm, S. P., and Spinhirne, J. D.: Tropical cloud-top height distributions revealed by the Ice, Cloud, and Land Elevation Satellite (ICESat)/Geoscience Laser Altimeter System (GLAS), J. Geophys. Res., 111, D12215, doi:10.1029/2005JD006705, 2006.

Devasthale, A. and Grassl, H.: Comparison of low brightness temperatures derived from the AVHRR thermal channels with insitu measurements in Antarctica, Int. J. Remote Sens., 30, 525-532, doi:10.1080/01431160802392588, 2009a.

Devasthale, A. and Grassl, H.: A daytime climatological distribution of high opaque ice cloud classes over the Indian summer monsoon region observed from 25-year AVHRR data, Atmos. Chem. Phys., 9, 4185-4196, doi:10.5194/acp-9-4185-2009, 2009b.

Di Girolamo, L., Bond, T. C., Bramer, D., Diner, D. J., Fettinger, F., Kahn, R. A., Martonchik, J. V., Ramana, M. V., Ramanathan, V., and Rasch, P. J.: Analysis of Multi-angle Imaging SpectroRadiometer (MISR) aerosol optical depths over greater India during winter 2001-2004, Geophys. Res. Lett., 31, L23115, doi:10.1029/2004GL021273, 2004.

$\mathrm{Fu}, \mathrm{Q} ., \mathrm{Hu}, \mathrm{Y}$., and Yang, Q.: Identifying the top of the tropical tropopause layer from vertical mass flux analysis and CALIPSO lidar cloud observations, Geophys. Res. Lett., 34, L14813, doi:10.1029/2007GL030099, 2007.

Fueglistaler, S., Dessler, A. E., Dunkerton, T. J., Folkins, I., Fu, Q., and Mote, P. W.: Tropical tropopause layer, Rev. Geophys., 47, RG1004, doi:10.1029/2008RG000267, 2009a.

Fueglistaler, S., Legras, B., Beljaars, A., Morcrette, J.-J., Simmons, A., Tompkins, A. M., Uppala, S.: The diabatic heat budget of the upper troposphere and lower/mid stratosphere in ECMWF reanalyses, Q. J. Roy. Meteorol. Soc., 135, 21-37, 2009 b.

Fueglistaler, S. and Fu, Q.: The impact of clouds on radiative heating in the tropical lower stratosphere, J. Geophys. Res., 111(D23), D23202, doi:10.1029/2006JD007273, 2006.
Gettelman, A. and P.M.de F. Forster: A climatology of the tropical tropopause layer, J. Meteorol. Soc. Jpn., 80, 911-942, 2002.

Gettelman, A., Kinnison, D. E., Dunkerton, T. J., and Brasseur, G. P.: The Impact of Monsoon Circulations on the Upper Troposphere and Lower Stratosphere, J. Geophys. Res., 109(D22), D22101, doi:10.1029/2004JD004878, 2004.

Gettelman, A., Salby, M. L., and Sassi, F.: Distribution and influence of convection in the tropical tropopause region, J. Geophys. Res., 107(D10), 4080, doi:10.1029/2001JD001048, 2002.

Goswami, B. N. and Ajaya Mohan, R. S.: Intraseasonal oscillations and interannual variability of the Indian summer monsoon, J. Climate, 14, 1180-1198, 2001.

Haladay, T. and G. Stephens: Characteristics of tropical thin cirrus clouds deduced from joint CloudSat and CALIPSO observations, J. Geophys. Res., 114, D00A25, doi:10.1029/2008JD010675, 2009.

Highwood, E., J. and Hoskins, B. J.: The tropical tropopause, Q. J. Roy. Meteorol. Soc., 124, 1579-1604, 1998.

Hong, G., Heygster, G., Notholt, J., and Buehler, S. A.: Interannual to diurnal variations in tropical and subtropical deep convective clouds and convective overshooting from seven years of AMSU-B measurements, J. Climate, 21(17), 4168-4189, doi:10.1175/2008JCLI1911.1, 2008.

Jain, A. R., Das, S. S., Mandal, T. K., and Mitra, A. P.: Observations of extremely low tropopause temperature over the Indian tropical region during monsoon and postmonsoon months: Possible implications, J. Geophy. Res., 111, D07106, doi:10.1029/2005JD005850, 2006.

James, R., Bonazzola, M., Legras, B., Surbled, K., and Fueglistaler, S.: Water vapor transport and dehydration above the convective outflow during Asian monsoon, Geophys. Res. Letts., 35, L20810, doi:10.1029/2008GL035441, 2008.

Jensen, E. J., Ackerman, A. S., and Smith, J. A.: Can overshooting convection dehydrate the tropical tropopause layer?, J. Geophys. Res., 112, D11209, doi:10.1029/2006JD007943, 2007.

Jiang, J. H., Wang, B., Goya, K., Hocke, K., Eckermann, S. D., Ma, J., Wu, D. L., and Read, W. G.: Geographical distribution and interseasonal variability of tropical deep convection: UARS MLS observations and analyses, J. Geophys. Res., 109, D03111, doi:10.1029/2003JD003756, 2004.

King, M. D., Menzel, W. P., Kaufman, Y. J., Tanré, D., Gao, B. C., Platnick, S., Ackerman, S. A., Remer, L. A., Pincus, R., and Hubanks, P. A.: Cloud and aerosol properties, precipitable water, and profiles of temperature and humidity from MODIS, IEEE Trans. Geosci. Remote Sens., 41, 442-458., 2003.

Liu, C. and Zipser, E. J.: Global distribution of convection penetrating the tropical tropopause, J. Geophys. Res., 110, D23104, doi:10.1029/2005JD006063, 2005.

Luo, Z. and Rossow, W. B.: Characterizing tropical cirrus lifecycle, evolution and interaction with upper tropospheric water vapor using Lagrangian trajectory analysis of satellite observations, J. Climate, 17, 4541-4563, 2004.

Park, M., Randel, W. J., Emmons, L. K., Bernath, P. F., Walker, K. A., and Boone, C. D.: Chemical isolation in the Asian monsoon anticyclone observed in Atmospheric Chemistry Experiment (ACE-FTS) data, Atmos. Chem. Phys., 8, 757-764, doi:10.5194/acp-8-757-2008, 2008.

Prasad, A. K., Singh, R. P., and Kafatos, M.: Influence of coal based thermal power plants on aerosol optical properties 
in the Indo-Gangetic basin, Geophys. Res. Lett., 33, L05805, doi:10.1029/2005GL023801, 2006.

Ramesh Kumar, M. R. and Uma, R. P. D.: A new criterion for identifying breaks in monsoon conditions over the Indian subcontinent, Geophys. Res. Lett., 31, L18201, doi:10.1029/2004GL020562, 2004.

Randel, W. J. and Park, M.: Deep convective influence on the Asian summer monsoon anticyclone and associated tracer variability observed with Atmospheric Infrared Sounder (AIRS), J. Geophys. Res., 111, D12314, doi:10.1029/2005JD006490, 2006.
Rossow, W. B. and Pearl, C.: 22-year survey of tropical convection penetrating into the lower stratosphere, Geophys. Res. Lett., 34, L04803, doi:10.1029/2006GL028635, 2007.

Sherwood, S. C., Chae, J.-H., Minnis, P., and McGill, M.: Underestimation of deep convective cloud tops by thermal imagery, Geophys. Res. Lett., 31, L11102, doi:10.1029/2004GL019699, 2004.

Sherwood, S. C. and Dessler, A. E.: On the control of stratospheric humidity, Geophys. Res. Lett., 27(16), 2513-2516, 2000.

Trischenko, A. P., Fedosejevs, G., Li, Z., and Cihlar, J.: Trends and uncertainties in thermal calibration of AVHRR radiometers onboard NOAA-9 to -16, J. Geophys. Res., 107(D24), 4778, doi:10.1029/2002JD002353, 2002. 